\title{
Membership Function Optimization of Fuzzy Logic System Using Cuckoo Search Algorithm for Peak Load Forecasting in Indonesian National Holiday
}

\author{
Andi Imran ${ }^{* 1}$, Imam Robandi ${ }^{2}$, Firdaus ${ }^{1}$, Ruslan$^{1}$, \\ Muhammad Yusuf Mappeasse ${ }^{1}$, Muhammad Ruswandi Djalal ${ }^{3}$ \\ ${ }^{1}$ Department of Electrical Engineering Education, Faculty of Engineering, Universitas Negeri Makassar \\ Jl. Daeng Tata Raya Parangtambung, Makassar, Indonesia \\ ${ }^{2}$ Department of Electrical Engineering, Faculty of Intelligent Electrical and Informatics Technology, \\ Institut Teknologi Sepuluh Nopember \\ Jl. Raya ITS, Sukolilo, Surabaya, Indonesia \\ ${ }^{3}$ Department of Mechanical Engineering, Energy Generation Study Program, State Polytechnic of \\ Ujung Pandang \\ J1. Perintis Kemerdekaan KM.10, Makassar, Indonesia \\ *Corresponding author, e-mail: andi_imran@unm.ac.id
}

\begin{abstract}
This study aims to analysis peak load prediction of Indonesian national holidays for Jawa-Bali electricity system. Forecasting applied using the Fuzzy Logic System (FLS) method combined with the Cuckoo Search Algorithm (CSA). CSA is used to determine the optimal membership function in fuzzy logic. Cuckoo search algorithm has a very good performance in terms of optimization. This method is applied for short-term load estimates on holidays/special days on the Jawa-Bali electricity system, Indonesia. The study used data from daily peak loads during Indonesian national holidays in 2014 on the Jawa-Bali electricity system. The data analyzed is the daily peak load documentation data for 4 days before national holidays and during national holidays in 2014. Testing the simulation results, it was found that the Fuzzy Logic System - Cuckoo Search Algorithm (FLS-CSA) method gives good forecasting results, this is evidenced by using the mean absolute percentage error (MAPE). Forecasting results using the Cuckoo Search Algorithm (CSA) optimization method on fuzzy logic membership functions for peak loads on national holidays on the Java-Bali $500 \mathrm{kV}$ electrical system give satisfactory results with an average forecasting error of $1.511314562 \%$
\end{abstract}

Keywords: Load Forecasting, Fuzzy Logic System, Cuckoo Search, MAPE

\section{Introduction}

Load estimation is very important for energy management in operating electric power. Precise estimates help electrical system operators in making decisions such as unit commitments, maintaining equipment, minimizing generation costs which are indispensable for power system reliability [1], [2].

There are several types of load forecasting that are used for example load forecasting for very short terms [3], [4], load forecasting for the short term [5]-[7], load forecasting for the medium term and load forecasting for the long term [8]-[10]. Research on load forecasting is very important for developed countries, especially short-term load forecasting due to energy market competition [11].

Forecasting the burden on special days/holidays is something unique because special days are different from ordinary days [12]. Many methods can be used for load forecasting. The methods that are often used are the conventional method and the intelligent method. The advantage of artificial intelligence methods lies in the techniques and algorithms that are not complicated. Satisfactory results without the need to solve complex non-linear mathematical equations.

In this study, a fuzzy logic system method was applied which was optimized using a search algorithm from the cuckoo bird for short-term load estimates, especially the top load on special days. 
Special days are used as national holidays. Cuckoo Search Algorithm (CSA) is an optimization method based on behavior of the cuckoo bird [13].

\section{Fuzzy Logic System}

Fuzzy logic was discovered by professor Zadeh in 1965 by using mathematical equations derived from set theory in describing ambiguous things into linguistic variables. Fuzzy logic is the development of Boolean set theory, which only recognizes two states, namely 0 and 1 , into a set that has membership values between 0 to 1 . Zadeh modifies set theory where each member has a continuous membership degree between 0 to 1 [14].

The process of classifying input data from crisp sets into membership degrees that have limits to become fuzzy sets is a fuzzification process or membership function. Various forms of fuzzy functions, for example:

\section{a. Function of Triangle}

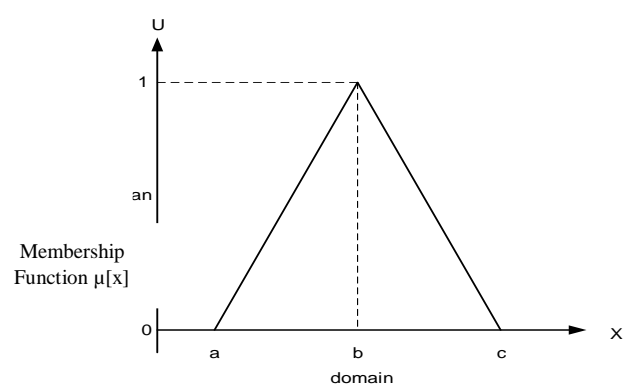

Fig. 1. Fuzzy membership function in the form of a triangle

The equation for the membership function of the triangle is:

$$
f(x, a, b, c)=\left\{\begin{array}{cc}
0, & x \leq a \\
\frac{x-a}{b-a}, & a \leq x \leq b \\
\frac{c-x}{c-b}, & b \leq x \leq c \\
0, & c \leq x
\end{array}\right\}
$$

or similar to the following equation:

$$
f(x, a, b, c)=\max \left(\min \left(\frac{x-a}{b-a}, \frac{c-x}{c-b}\right), 0\right)
$$

$\mathrm{X}$ is input parameter, a and $\mathrm{c}$ expressed leg of triangle, while $b$ declares apex of triangle.

b. Trapezoid function

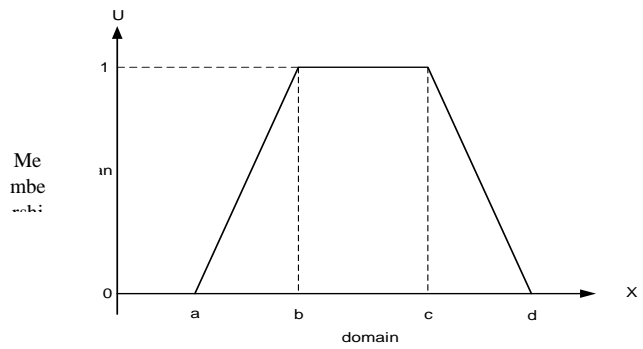

Fig. 2. Fuzzy membership function in the form of a trapezoidal

The equation for the membership function of the trapezoidal is:

$$
f(x, a, b, c)=\left\{\begin{array}{cc}
0, & x \leq a \\
\frac{x-a}{b-a}, & a \leq x \leq b \\
1, & b \leq x \leq c \\
\frac{d-x}{d-c}, & c \leq x \leq d \\
0, & d \leq x
\end{array}\right\}(3)
$$

or $f(x, a, b, c)=\max \left(\min \left(\frac{x-a}{b-a}, 1, \frac{d-x}{d-c}\right), 0\right)$

parameter $x$ is input, a and d showing tip of trapezoidal leg, then $b$ and $c$ represent the tip of the trapezoidal shoulder.

The basic operations on fuzzy sets A and B of X with membership levels $\mu A(x)$ and $\mu B(x)$ for $x \in X$ are as follows:

a. Complement

The complement of the set A represents all components of the set that are not in the set A

$$
\mu \bar{A}(x)=1-\mu A(x)
$$

b. Union

The Union or OR set operation on two fuzzy sets $\mathrm{A}$ and $\mathrm{B}$ is expressed in the following equation:

$$
\mu A \cup \mu B=\max (\mu(A), \mu(B)) ; x \in X
$$

c. Intersection

The intersection AND operation on two fuzzy sets A and B can be interpreted as follows:

$$
\mu A \cap \mu B=\min (\mu(A), \mu(B)) ; x \in X
$$

\section{Cuckoo Search Algorithm}

Cuckoo Search is a heuristic algorithm based on the behavior of the cuckoo bird that has been proposed by Yang and Deb [13]. Cuckoos have a unique reproductive strategy by laying eggs in the place of other birds, which may be different breeds or species. To make it easier to describe the Cuckoo search, three rules were made as references, namely: a. The cuckoo laying eggs in the nest is 
chosen at random; b. Quality nests with the best eggs pass to the next generation; c. The number of existing host nests is considered fixed, and the eggs that hatch are found by the host bird which has a probability of $p_{a} \in[0,1]$. In this situation, the host bird has a choice, namely to leave the nest or throw away the eggs and then build a new nest. Therefore this approach can be assumed with the $p_{a}$ fraction for $\mathrm{n}$ nests replaced with new nests randomly. When continuing with the new generation $\mathrm{x}^{(\mathrm{t}+1)}$, the step randomization process with Lévy Flights is used as in the equation:

$$
x_{i}^{(t+1)}=x_{i}^{(t)}+\alpha \oplus \operatorname{levy}(\lambda)
$$

Hereby a $>0$ is the step size which corresponds to the order in which the problem is being executed. Meanwhile, Lévy $(\lambda)$ represents a function of the Lévy Flight position equation, which can be represented as follows:

$$
\text { levy: } u=t^{-\lambda},(1<\lambda \leq 3)
$$

\section{Forecasting Peak Load for National Holidays using FLS-CSA}

In executing the forecasting of peak load for national holidays using FLS-CSA, three stages are carried out, namely before processing, processing, and after processing [6].

\section{IV.1. Before Processing}

Prior to processing is the preparation of peak load data for national holidays to obtain LD, max WD, VLD and TLD. LD is Load Difference, max WD is Maximum Weekdays, VLD is Variation Load Difference and TLD is Typical Load Difference. LD is sought to obtain the difference in load in the four days before the holiday with the equation:

$$
\begin{aligned}
& L D_{M A X}(i)=\frac{\operatorname{MaxSD}(i)-\operatorname{Max} W D(i)}{\operatorname{Max} W D(i)} \times 100 \\
& \operatorname{MaxWD}_{(i)}=\frac{W D_{(i) d-4}+W D_{(i) d-3}+W D_{(i) d-2}+W D_{(i) d-1}}{4}
\end{aligned}
$$

Where maxSD(i) is the peak load on the special day and maxWD is the average maximum load 4 days before the holiday. TLD ${ }_{\mathrm{MAX}}$ is obtained by averaging $L D_{M A X}$ according to previous years. then solve for VLD $\mathrm{VAX}_{\mathrm{MAX}}$ which is the difference between LD $_{\text {MAX }}$ and TLD $D_{\text {MAX }}$ expressed in:

$$
\begin{aligned}
& V L D_{\text {max }}(i)=L D_{\text {max }}(i)-T L D_{\text {max }}(i) \\
& T L D_{\text {max }}(i)=\frac{L D_{\text {max }}(i-1)+L D_{\text {max }}(i-2)+L D_{\text {max }}(i-3)}{3}
\end{aligned}
$$

Table 1 and Table 2 display MaxWD and LD max peak load data Eq. (12) and (13).

\section{IV.2. Processing}

Process of data management by modeling load forecasting on national holidays using FLS-CSA. The process is run on the membership function of the Fuzzy Logic System. Membership function optimized using cuckoo algorithm.

Fuzzy IF-THEN rules used in the FLS-CSA method to predict the largest electricity load on national holidays which are expressed as:

$$
\text { IF } X \text { is } A_{i} A N D Y \text { is } B_{i} \text { THEN } Z \text { is } C_{i}
$$

$\mathrm{X}$ and $\mathrm{Y}$ input process using Membership Function, there are eleven membership functions used [6] namely Negative Very Big (NVB), Negative Big (NB), Negative Medium (NM), Negative Small (NS), Negative Very Small (NVS), Zero (ZE), Positive Very Small (PVS), Positive Small (PS), Positive Medium (PM), Positive Big (PB), and Positive Very Big (PVB).

The use of fuzzy rules is shown in Table 3.

TABLE I

PEAK LOAD In 2014

\begin{tabular}{l|l|l|l|l}
\hline \hline \multicolumn{5}{c}{ National Holidays Peak Load in 2014 $(\mathbf{M W})$} \\
\hline WD(i)d-4 & WD(i)d-3 & WD(i)d-2 & WD(i)d-1 & MaxSD(i) \\
19786,00 & 19025,00 & 19462,00 & 18046,00 & 16720,00 \\
22450,00 & 22217,00 & 22048,00 & 20529,00 & 18474,00 \\
22789,00 & 22714,00 & 22489,00 & 22573,00 & 22375,00 \\
20106,00 & 22259,00 & 22230,00 & 21884,00 & 19652,00 \\
21438,00 & 20377,00 & 19070,00 & 20508,00 & 19425,00 \\
22843,00 & 21480,00 & 20429,00 & 21913,00 & 20687,00 \\
19707,00 & 17920,00 & 16180,00 & 15214,00 & 14227,00 \\
17920,00 & 16180,00 & 15214,00 & 14227,00 & 14590,00 \\
21974,00 & 22274,00 & 22105,00 & 21959,00 & 19744,00 \\
20429,00 & 21913,00 & 20687,00 & 22326,00 & 20837,00 \\
20106,00 & 22259,00 & 22230,00 & 21884,00 & 19652,00 \\
22276,00 & 21888,00 & 20491,00 & 19129,00 & 19204,00 \\
21215,00 & 21189,00 & 21102,00 & 20562,00 & 18395,00 \\
20531,00 & 22006,00 & 23022,00 & 22602,00 & 20674,00 \\
\hline \hline
\end{tabular}

TABLE II

VLD MAX FOR WAISAK 2013 AND 2014

\begin{tabular}{ccccc}
\hline \hline Year & MaxWD & LDMax & TLD Max & VLD Max \\
\hline 2014 & 21573,5 & $-13,496$ & $-7,5221$ & $-5,9736$ \\
2013 & 19491,8 & $-10,167$ & $-6,9931$ & $-3,174$ \\
\hline \hline
\end{tabular}


TABLE III

. VLD MAX FOR WAISAK 2013 AND 2014

\begin{tabular}{cccc}
\hline \hline \multirow{2}{*}{$\begin{array}{c}\text { No. } \\
\text { Rules }\end{array}$} & Antecendent & Consequent \\
& $\mathbf{X}$ & $\mathbf{Y}$ \\
\hline 1 & ZE & NVS & ZE \\
2 & PB & ZE & NVS \\
3 & PVS & ZE & PVB \\
4 & PVS & PVB & NVS \\
5 & PVS & NVS & PS \\
6 & NS & PS & PVS \\
7 & NVS & PVS & NVS \\
8 & NVS & NVS & ZE \\
9 & ZE & ZE & NVS \\
10 & ZE & NVS & PVS \\
11 & PVS & PVS & ZE \\
12 & PVS & PVS & ZE \\
13 & NS & ZE & NS \\
14 & NM & NS & PVS \\
\hline \hline
\end{tabular}

The rules in Table 3 can be observed in the rule editor as follows:

(Rule 1) IF X is ZE AND Y is NVS THEN Z is ZE

(Rule 14) IF X is NM AND Y is NS THEN Z is PVS

The input variables $\mathrm{X}, \mathrm{Y}$ and $\mathrm{Z}$ are VLDmax for holiday data. $X$ is the VLDmax (i) of the same holiday in the year preceding the forecast year. $\mathrm{Y}$ is VLDmax (i) the holiday adjacent to the predicted holiday in the previous year. $\mathrm{Z}$ is the predicted result of VLDmax (i). The value of the membership function is processed using the CSA optimization method.

\section{IV.3. After Processing}

The last stage is after processing, which is looking for differences in peak load forecasting which can be announced as follows:

$$
\text { Forecast } L D_{\text {MAX }}(i)=\text { Forecast } V L D_{M A X}(i)+T L D_{M A X}(i)(15)
$$

After getting the estimated load difference, the estimated peak load on national holidays can be seen:

$$
P_{M A X}^{\prime}(i)=\operatorname{MaxWD}(i)+\frac{\left(\text { Forecast } L D_{\text {MAX }} x \operatorname{MaxWD}(i)\right)}{100}
$$

The benchmark for the performance of the method used is by applying the absolute error equation. The smaller the error obtained, the better the accuracy of the proposed method. Absolute error can be obtained as:

$$
\text { Error }=\left|\frac{P_{\text {actual }}-P_{\text {forecast }}}{P_{\text {actual }}}\right| x 100 \%
$$

\section{Result and Discussion}

The peak load data used is data on national holidays for the Indonesian Java-Bali system. National holiday data is processed using the Fuzzy Logic System - Cuckoo Search Algorithm (FLSCSA) method. The Fuzzy Logic System (FLS) method is used as a comparison with the proposed method. The results of the validation of the FLSCSA method for forecasting the peak load of national holidays obtained very good results with a Mean Absolute Percentage Error (MAPE) of $1.511314562 \%$. MAPE obtained by using FLS is $1.627702763 \%$. More detailed results are obtained in table 4 and figure 3 . Table 4 is the detailed result of forecasting the peak load of national holidays. Figure 3 is the result of forecasting the peak load of national holidays plotted from table 4 .

Basically, Figure 3 is the same as Table 4, Figure 3 is the result of plotting from Table 4. Based on Table 4, the biggest error occurred on the day of Proklamasi Kemerdekaan RI. The error using the FLS method is $8.56 \%$ while the error using the FLS-CSA method is $8.37 \%$. The smallest error obtained using the FLS method was $0.05 \%$ on the day of Idul Fitri II while the smallest error obtained using the FLS-CSA method was $0.04 \%$ on the day of Nyepi.

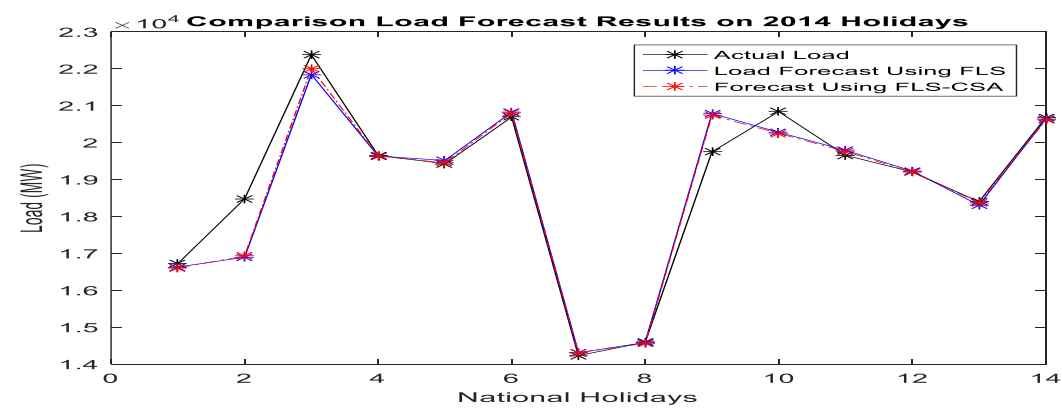

Fig. 3. Comparison of peak load forecasting results using FLS and FLS-CSA 
TABLEIV

Results of PEAK LOAD FORECASTING ON NATIONAL Holidays IN 2014.

\begin{tabular}{|c|c|c|c|c|c|c|}
\hline \multirow[b]{2}{*}{ No } & \multirow[b]{2}{*}{ Holidays Name } & \multirow[b]{2}{*}{$\begin{array}{l}\text { Actual } \\
\text { (MW) }\end{array}$} & \multicolumn{2}{|c|}{ Fuzzy Logic System (FLS) } & \multicolumn{2}{|c|}{ FLS-CSA } \\
\hline & & & $\begin{array}{c}\text { Forecast } \\
\text { (MW) }\end{array}$ & $\begin{array}{c}\text { Absolute } \\
\text { Error (\%) }\end{array}$ & $\begin{array}{c}\text { Forecast } \\
(\mathrm{MW})\end{array}$ & $\begin{array}{c}\text { Absolute } \\
\text { Error (\%) }\end{array}$ \\
\hline 1 & Tahun Baru Masehi & 16720,00 & 16627,35286 & 0,554109672 & 16599,05759 & 0,723339751 \\
\hline 2 & Proklamasi Kemerdekaan RI & 18474,00 & 16891,56861 & 8,565721498 & 16926,85881 & 8,374695202 \\
\hline 3 & IdulAdha & 22375,00 & 21842,96323 & 2,377817985 & 22009,98773 & 1,631339767 \\
\hline 4 & Tahun Baru Hijriyah & 19652,00 & 19632,92551 & 0,097061331 & 19631,77966 & 0,102892019 \\
\hline 5 & Maulid Nabi Muhammad SAW & 19425,00 & 19512,05213 & 0,448144794 & 19450,25449 & 0,13001025 \\
\hline 6 & Isra Mi'raj & 20687,00 & 20824,57442 & 0,66502838 & 20796,64662 & 0,530026706 \\
\hline 7 & Idul Fitri I & 14227,00 & 14306,39202 & 0,55803768 & 14306,15045 & 0,556339687 \\
\hline 8 & Idul Fitri II & 14590,00 & 14582,06756 & 0,054369009 & 14558,46208 & 0,216161206 \\
\hline 9 & WafatnyaYesus Kristus & 19744,00 & 20784,14859 & 5,268175602 & 20738,00557 & 5,034469058 \\
\hline 10 & KenaikanYesus Kristus & 20837,00 & 20276,38292 & 2,690488457 & 20244,50283 & 2,843485974 \\
\hline 11 & Natal & 19652,00 & 19788,80586 & 0,696142158 & 19756,72215 & 0,532882902 \\
\hline 12 & Nyepi & 19204,00 & 19227,23717 & 0,121001709 & 19196,1952 & 0,040641553 \\
\hline 13 & Tahun Baru Imlek & 18395,00 & 18301,48665 & 0,508362852 & 18372,83937 & 0,120470952 \\
\hline 14 & Waisak & 20674,00 & 20636,08852 & 0,183377562 & 20607,50232 & 0,321648841 \\
\hline \multicolumn{3}{|c|}{ Mean Absolute Percentage Error (MAPE) } & & 1,627702763 & & 1,511314562 \\
\hline
\end{tabular}

\section{Conclusion}

Fuzzy Logic System - Cuckoo Search Algorithm (FLS-CSA) is applied in this research to forecast the highest load on national holidays in 2014. Data on the Java-Bali $500 \mathrm{kV}$ electricity system is used. This method shows more accurate results than unoptimized FLS.

\section{References}

[1] V. Dehalwara, A. Kalama, M. L. Kolheb, and A. Zayegh, A, "Electricity load forecasting for Urban area using weather forecast information," IEEE Int Conf on Power and Renewable Energy 2016, Shanghai, China, 21-23 Oct. 2016. pp. 355 - 359, 2016.

[2] M. Lekshmi and K. N. A. Subramanya, "Short-Term load forecasting of $400 \mathrm{kV}$ grid substation using RTool and study of influence of ambient temperature on the forecasted load," IEEE Int Conf on Adv Comp and Comm Paradigms (ICACCP), 2019.Gangtok, India,25-28 Feb, 2019.

[3] M. Alamaniotis, "Synergism of deep neural network and ELM for smart very-short-term load forecasting," IEEE PES Innovative Smart Grid Technologies Europe (ISGT-Europe) 2019. Bucharest, Romania,29 Sept.-2 Oct, 2019.

[4] L. C. M. D. Andrade, M. Oleskovicz, A. Q. Santos, D. V. Coury, and R. A. S. Fernandes, "Very shortterm load forecasting based on NARX recurrent neural networks," IEEE PES General Meeting | Conference \& Exposition. National Harbor, MD, USA, 27-31 July, 2014.
[5] G. Yan, T. Han, W. Zhang, and S. Zhao, "Short-term load forecasting of smart grid based on load spatial temporal distribution," IEEE Innovative Smart Grid Technologies - Asia (ISGT Asia), Chengdu, China, 21-24 May. pp. 781-785, 2019.

[6] A. Imran, I. M. Y. Negara, and I. Robandi, "Peak load forecasting on national holiday using fuzzyfirefly algorithm at Jawa-Bali electricity system in Indonesia," Int. Journal of Civil Eng. and Tech (IJCIET), 9(6). 1001-1015, 2018.

[7] A. Imran, I. M. Y. Negara, and I. Robandi, "Peak load forecasting on national holiday using fuzzycuckoo for Jawa-Bali system in Indonesia," Int Journal of Eng \& Tech (IJET), 7(6). 5565-5569, 2018.

[8] L. Jinlian, Z. Yufen, and L. Jiaxuan, "Long and medium term power load forecasting based on a combination model of GMDH, PSO and LSSVM," IEEE,2017 29th Chinese Control And Decision Conference (CCDC). Chongqing, China, 28-30 May, pp. 964-969, 2017.

[9] W. Xue, C. Li, X. Mao, X. Li, L. Zhao, and X. Zhao, "Medium and long term load forecasting of regional power grid in the context of economic transition," 2nd IEEE Conference on Energy Internet and Energy System Integration (EI2),.Beijing, China,2022 Oct. 2018.

[10]F. Gao, "Application of Improved Grey Theory Prediction Model in Medium-Term Load Forecasting of Distribution Network," IEEE, 2019 Seventh International Conference on Advanced Cloud and Big Data (CBD).Suzhou, China, 21-22 Sept. pp. $151-155,2019$.

[11]R. Weron, "Modeling and forecasting electricity loads and prices" Published by John Wiley \& Sons, ISBN-13: 978-0-470-05753-7, 2006. 
[12] K.-H. Kim, H.-S. Youn, and Y.-C. Kang, "Shortterm load forecasting for special days in anomalous load conditions using neural networks and fuzzy inference method," IEEE Transactions on Power Systems, 15(2). 599 - 565, 2000.

[13]X. S. Yang, and S. Deb, "Cuckoo Search via Le'vy Flights," IEEE, 2009 World Congress on Nature \& Biologically Inspired Computing (NaBIC), Coimbatore, India, 9-11 Dec, pp. 210 - 214, 2009.

[14]L. A. Zadeh, "Fuzzy Sets," Elsevier, Information and Control. 8 (3), pp. 338 - 353, 1965.

\section{Authors' information}

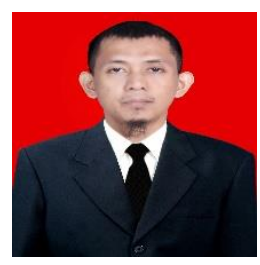

Andi Imran is a lecturer at the Department of Electrical Engineering Education, Faculty of Engineering, Universitas Negeri Makassar. He received Ph.D degree in Electrical Engineering from Institut Teknologi Sepuluh Nopember Surabaya, Indonesia. His research interests power system engineering and control engineering.Email: andi_imran@unm.ac.id

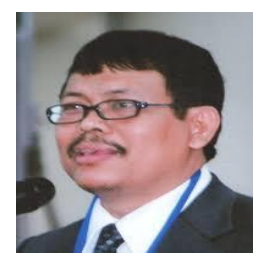

Imam Robandi is a lecturer at the Department of Electrical Engineering, Faculty of Intelligent Electrical and Informatics Technology, Institut Teknologi Sepuluh Nopember. He received Ph.D degree in Electrical Engineering from Institut Teknologi Sepuluh Nopember Surabaya, Indonesia. His research interests power system engineering and control engineering. He received Doctor of Design and Information Engineering at Tottori University in Japan. Since 2008, he is a Professor in Electrical Engineering at Institut Teknologi Sepuluh Nopember. His research is about Dynamic Stability problem of large scale electrical power system with intelligent control, optimization control, adaptive control and intelligent control. He has awarded for encounment of research and development from Institute of electrical engineer of Japan (IEEJ) in 2000.

Email : robandi@ee.its.ac.id

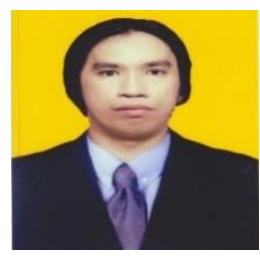

Firdaus is a lecturer at the Department of Electrical Engineering Education, Faculty of Engineering, Universitas Negeri Makassar. He received M. Eng degree in Electrical Engineering from Institut Teknologi Sepuluh Nopember Surabaya, Indonesia. His research interests power system engineering. Email: dauselektro@unm.ac.id

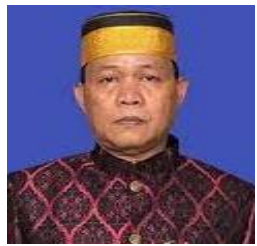

Ruslan is a lecturer at the Department of Electrical Engineering Education, Faculty of Engineering, Universitas Negeri Makassar. He received Ph.D degree in Education Technology from Universitas Negeri Jakarta, Indonesia. His research interests power electronic.

Email : ruslan.ft@unm.ac.id

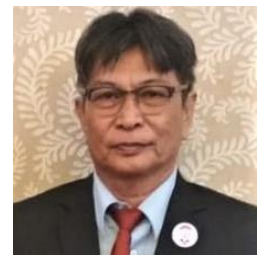

Muhammad Yusuf Mappeasse is a lecturer at the Department of Electrical Engineering Education, Faculty of Engineering, Universitas Negeri Makassar. He received Ph.D degree in Education Technology from Universitas Negeri Makassar, Indonesia. His research interests power electronic.

Email : muh.yusuf.mappeasse@unm.ac.id

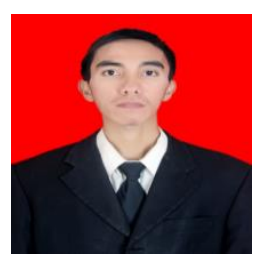

Muhammad Ruswandi Djalal was born in Ujung Pandang, on march 11, 1990. He obtained his bachelor degree from State Polytechnic of Ujung Pandang (Makassar, Indonesia) in 2012 majoring Energy Engineering. Then, he finished his master degree from SepuluhNopember Institute of Technology, (Surabaya, Indonesia) in 2015 in the field of Electrical Engineering. His research is mainly in Power System Stability, Renewable Energy, and Artificial Intelligent. He is currently a lecturer in the Department of Energy Generation, State Polytechnic of Ujung Pandang.

Email : wandi@poliupg.ac.id 